\title{
Dampak Pengembangan Objek Wisata Pantai Tiram Terhadap Perekonomian Masyarakat
}

\author{
Sahari Syah Syafarini ${ }^{1}$ M. Fachri Adnan ${ }^{2}$ \\ Ilmu Administrasi Negara, Fakultas Ilmu Sosial,Universitas Negeri Padang \\ Email: fachriadnan@fis.unp.ac.id, Saharisyahsafarini97@gmail.com;
}

\begin{abstract}
This study aims to see the extent to which the impact of the development of oyster beach tourism objects on the economy of the Tapakis village community carried out by the tourism and sports office of Padang Pariaman district and to find out what are the obstacles that occur when developing oyster beach tourism. This research is based on the existence of problems in the tourism object of the Tapakis oyster beach such as development that has not been maximized and tourist facilities that are not well managed. This research uses qualitative research using descriptive methods. The informants in this study in this study, namely the Tourism Development Sector, the Promotion and Creative Economy Sector, the Wali Nagari Tapakis, the Tourism Awareness Group and Community Figures. The data of this research are primary data and secondary data. Data collection techniques are carried out by means of interviews and documentation studies, as well as testing the validity of the data by using triangulation techniques and using reference materials. The data analysis technique in this study was carried out by summarizing the records that were found in the field and assisted by data collection tools such as cellphone recorders with informants while in the field, after which a conclusion was obtained. The results of this study indicate that the impact of the development of oyster beach tourism objects on the economy the community of Tapakis village, Padang Pariaman district. The youth tourism and sports office as well as Pokdarwis members have carried out promotions such as placing advertisements, billboards, magazines, newspapers, browsers, Facebook and Instagram. Currently, the facilities at Oyster Beach are adequate, but these facilities have not been well managed at this time and from an environmental perspective it is still not clean enough. the level of visits to tourist objects has started to increase now compared to previous years as well as the economic income of the people around oyster beach tourism has started to improve as well today.
\end{abstract}

Keywords: Tourism Development, Community Economy

\section{PENDAHULUAN}

Menurut Sefira, (2013) melalui pengamatannya terhadap Analisis Strategi Pengembangan Pariwisata Daerah (Studi Pada Dinas Kebudayaan Dan Pariwisata Kabupaten Nganjuk) mengatakan bahwasannya objek wisata yang terdapat di Kabupaten Nganjuk ini memiliki pesona yang indah, namun Pemerintah Daerah Kabupaten Nganjuk ini masih kurang maksimal didalam melancarkan pengembangan objek wisata tersebut. Kenyataannya belum berlangsungnya programprogram mengenai peningkatan rekreasi daerah lantaran terganggu dengan dana yang seadanya dan belum adanya aturan hukum atau peraturan daerah yang membentuk khusus berkenaan mengenai cara peningkatan sektor wisata di daerah Kabupaten Nganjuk sehingga persiapan atau rancangan yang sudah dikerjakan oleh Dinas Kebudayaan Dan Pariwisata Daerah Kabupaten Nganjuk bersama para koordinasinya di lapangan di empat objek wisata tersebut belum bisa diselenggarakan dengan baik dan menyeleruh. Sedangkan penelitian yang saya temukan dilapangan mengenai Dampak Pengembangan Objek Wisata Pantai Tiram Terhadap Perekonomian Masyarakat masih mengalami berbagai permasalahan seperti: 1) jalur jalan masuk objek wisata yang masih kecil sehingga wisatawan yang berkunjung dengan bus 
Jurnal Ilmu Sosial dan Pendidikan

http://ejournal.mandalanursa.org/index.php/JISIP/index

Terakreditasi Peringkat 5 (No. SK: 85/M/KPT/2020)

pariwisata agak susah masuk ke lokasi objek wisata karena jalannya sempit, 2) transportasi menuju objek wisata yang masih minim sehingga wisatawan yang ingin mengunjungi objek wisata pantai tiram harus menggunakan transfortasi pribadi, 3) sarana dan prasarana objek wisata yang tidak terkelola dengan baik, 4) gerbang masuk objek wisata terlihat tidak terawat dan kumuh begitu juga dengan tamantaman yang ada di dalam wisata Pantai Tiram tidak tertata dengan baik, 5) serta pemerintah daerah yang kurang menggencarkan promosi objek wisata pantai tiram ini.

\section{TINJAUAN PUSTAKA}

\section{Konsep Pariwisata}

Istilah kepariwisataan merupakan suatu gabungan dari beberapa cakupan seperti wisata, kepariwisataan dan pariwisata. Kepariwisataan ini adalah segala bentuk tindakan yang dilakukan oleh wisatawan yang dilengkapi dengan sarana prasarana dan infastruktur yang mendukung yang disediakan oleh para stakeholder pariwisata. (Khusnul,2017:58). Pariwisata adalah beragam bentuk kegiatan wisata dan didukung dengan bermacam sarana dan prasarana serta fasilitas yang diberi oleh Masyarakat, Pengusaha, Pemerintah, Dan Pemerintah Daerah. (Rony,2016:24) dengan adanya objek wisata yang dapat memajukan usaha-usaha ekonomi yang saling menata dan membantu aktivitas wisata sehingga bisa menaikkan pendapatan masyarakat setempat.

Dapat disimpulkan bahwa pariwisata yaitu suatu langkah untuk mencapai tujuan dalam suatu kegiatan pariwisata dengan jangka waktu tertentu dan Didalam melakukan pengembangan pariwisata ini juga bertujuan untuk menigkatkan kualitas pariwisata agar dapat meningkatkan jumlah pengunjung yang banyak bagi destinasi wisata.

\section{Strategi Pengembangan Objek Wisata}

Menurut Muhammad Arif, (2017) starategi pengembangan objek wisata adalah sebagai berikut: melakukan pengarahan supaya dapat meningkatkan serta memajukan pengetahuan masyarakat pengenai perlunya
Vol. 5. No. 1 Januari 2021

p-ISSN: 2598-9944 e- ISSN: 2656-6753

masyarakat sadar wisata, mengembangkan atraksi pariwisata, membangun dan mengadakan aksesibilitas pariwisata, melakukan pemberdayaan, melaksanakan pengorganisasian dengan kelompok privat untuk menanamkan aset dan mengadakan fasilitas sarana dan prasarana objek wisata.

Sedangkan menurut Dewi, (2015: 104) bahwa strategi pengembangan objek wisata ada beberapa hal yaitu sebagai berikut:

a. Strategi pengembangan fasilitas wisata.

Strategi pengembangan fasilitas wisata adalah suatu usaha untuk meningkatkan sarana dan prasaran di suatu tempat wisata yang tujuannya untuk memenuhi kebutuhan wisatawasan.

b. Strategi pengembangan infrastruktur.

Strategi pengembangan infrastruktur adalah suatu usaha yang dilakukan untuk melakukan perubahan pembangunan prasarana di kawasan wisata atau melakukan pembangunan yang lebih baik lagi untuk penunjang utama di kawasan wisata agar dapat menarik wisatawan untuk berkunjung.

c. Strategi pengembangan SDM.

Strategi pengembangan SDM merupakan suatu upaya yang harus dilakukan oleh suatu instansi maupun perusahaan dalam membentuk kemampuan dan keterampilan yang dimiliki setiap anggotanya.

d. Strategi pengembangan pengelolaan lingkungan..

Strategi pengembangan pengelolaan lingkungan merupakan salah usaha yang dilakukan untuk menjaga dan melestarikan suatu tempat atau lingkungan di kawasan wisata.

e. Strategi pengembangan pasar dan pemasaran.

Strategi pengembangan pasar dan pemasaran adalah suatu cara untuk menarik pelanggan baru sebanyak mungkin dengan menawarkan produk yang baru sedangkan pemasaran yaitu sebuah usaha yang dilakukan untuk 
Jurnal Ilmu Sosial dan Pendidikan

http://ejournal.mandalanursa.org/index.php/JISIP/index

Terakreditasi Peringkat 5 (No. SK: 85/M/KPT/2020)

meningkatkan penjualan dari hasil produk.

f. Strategi pengembangan kelembagaan.

Strategi kelembagaan yaitu sebuah usaha atau cara yang dilakukan pemerintah didalam melakukan pembaharuan untuk wisata yang akan dibangun dan dikelolanya.

\section{Tahap Pengembangan Pariwisata}

Pada dasarnya dalam dalam menentukan posisi pariwisata maka pariwisata harus mengikuti perkembangan zaman saat ini Menurut Cooper and Jakson dalam Juita, (2018:5) tahapan tersebut terdiri dari:

a. Tahap Pengembangan (development) dengan adanya peninjauan lokal yang dilakukan akan dapat menujukkan kenaikan jumlah kunjungan wisatawan secara meningkat, pengendalian yang dilakukan oleh lembaga lokal yang susah membuahkan hasil, masuknya industri wisata dari luar dan popularitas kawasan wisata ini dapat menyebabkan kerusakan lingkungan alam dan sosial budaya sehingga diperlukan adanya campur tangan kontrol penguasa lokal maupun nasional.

b. Tahap Penurunan kualitas (decline) hampir semua pengunjung telah mengganti kunjungannya ke daerah tujuan tempat rekreasi lain.

c. Tahap Konsolidasi (consolidation) ini ditunjukkan oleh pengurangan tingkat perkembangan kunjungan wisatawan.

d. Tahap Eksplorasi (explorasi) yang berhubungan dengan penemuan (discovery) adalah salah satu tempat sebagai potensi wisata baru ditemukan oleh pengunjung, pelaku pariwisata, maupun pemerintah.

e. Tahap Keterlibatan (involvement) yang diikuti oleh peninjauan lokal, dimana biasanya dilakukan oleh masyarakat lokal.

f. Tahap Kestabilan (stagnation) jumlah pengunjung terbanyak yang telah dicapai dilingkungan ini mulai
Vol. 5. No. 1 Januari 2021

p-ISSN: 2598-9944 e- ISSN: 2656-6753

ditinggalkan karena tidak mode lagi, kunjungan kembali dan para pedagang menggunakan sarana dan prasarana yang ada.

\section{Tujuan Pengembangan pariwisata}

Menurut Undang-undang Nomor 10 tahun 2009 pada Pasal 4 tentang kepariwisataan tujuan pengembangan pariwisata adalah sebagai berikut: untuk Memajukan perkembangan ekonomi, menghapus kemiskinan, memajukan kesejahteraan rakyat, menjaga alam, lingkungan dan sumber daya, mengembangkan kebudayaan, memupuk cinta tanah air, memperkokoh jati diri dan kesatuan bangsa, mempererat persahabatan antar bangsa dan mengatasi pengangguran,

\section{Ekonomi Politik}

Menurut Isma, (2011:94) ekonomi politik adalah suatu aspek untuk mengamati dan menganalisis. Didalam melakukan analisis sesuatu yang terjadi maka terdapat 4 bagian penting dari perspektif ekonomi politik berdasarkan dari perbedaan sosial tranformasi historis yang membahas mengenai kelengkapan dari hubungan sosial yang memicu bidang ekonomi sosial dan budaya, yang bertanggungjawab pada falsafat moral dan memiliki ketertarikan terhadap nilai sosial serta prinsip sosial dan moral.

\section{METODE PENELITIAN}

Jenis penelitian ini adalah penelitian kualitatif dengan menggunakan metode deskriptif, penelitian dilakukan di Pantai Tiram Nagari Tapakis Kecamatan Ulakan Tapakis Kabupaten Padang Pariaman Provinsi Sumatera Barat. Dengan menggunakan informan penelitian yaitu melalui teknik purposive sampling sampling yaitu dengan memastikan informan dan peninjauan tertentu yang akan dapat memperoleh data secara maksimal. Informan dalam penelitian Bidang Pengembangan Pariwisata,Seksi Pengembang Objek Dan Daya Tarik Wisata, Seksi Pengembang SDM Pariwisata, Bidang Promosi 
Jurnal Ilmu Sosial dan Pendidikan

http://ejournal.mandalanursa.org/index.php/JISIP/index

Terakreditasi Peringkat 5 (No. SK: 85/M/KPT/2020)
Vol. 5. No. 1 Januari 2021

p-ISSN: 2598-9944 e- ISSN: 2656-6753
Dan Ekonomi Kreatif, Seksi Usaha Dan Promosi Wisata,Seksi Data Dan Pelayanan Informasi,Wali Nagari Tapakis, Toko Masyarakat Dan Pedagang Di Kawasan Wisata Pantai Tiram, serta teknik pengumpulan data dilakukan dengan cara wawancara dan studi dokumentasi.

\section{HASIL DAN PEMBAHASAN}

Berdasarkan hasil penelitian yang diperoleh mengenai "Dampak Pengembangan Objek Wisata Pantai Tiram Terhadap Perekonomian Masyarakat Studi Di Nagari Tapakis Kecamatan Ulakan Tapakis Kabupaten Padang Pariaman" yang peneliti lakukan di Pantai Tiram Kabupaten Padang Pariaman. Adapun yang akan dibahas dalam pembahasan ini adalah masalah yang terkait dengan rumusan masalah yang telah penulis rumuskan serta akan dijawab dengan menggunakan teori serta diperkuat dengan temuan penelitian yang ada. Menurut Dewi, (2015:104) bahwa strategi pengembangan objek wisata mencangkup beberapa hal yaitu sebagai berikut:

\section{Strategi Pengembangan Objek Wisata Pantai Tiram}

Strategi pengembangan fasilitas wisata adalah suatu fasilitas yang dapat membawa bekerja dengan efektif disuatu tempat rekreasi yang tujuannya akan dapat membantu semua keperluan pengunjung, akan tetapi bukan meningkatkan kemajuan secara langsung melainkan sebaliknya meningkat disaat yang bersamaan maupun sesudah atraksi mulai berkembang. Berdasarkan hasil penelitian keberadaan sarana dan prasarana menjadi penunjang di objek wisata pantai Tiram berupa: ada dua musholla tujuannya agar untuk memudahkan wisatawan yang beragama muslim untuk melaksanakan ibadahnya, ada dua buah toilet, lahan parkir, pentas seni, plaza kuliner,board walk dan selain itu juga ada beberapa rumah makan. Sedangkan penelitian yang dilakukan Atun,(2020) sarana dan prasarana penunjang wisata dalam sebuah destinasi dapat berupa fasilitas yang dapat dinikmati oleh wisatawan selama dilokasi. Di dalam penelitian ini fasilitas wisata sangat berperan penting untuk meningkatkan kunjungan wisatawan semangkin lengkap sarana dan prasara di objek wisata tersebut maka semangkin meningkat tingkat kunjunga, dengan kelengkapan fasilitas yang ada di wisata ini juga akan berpengaruh baik pada pendapatan masyarakat di kawasan objek wisata ini.

Strategi pengembangan infrastruktur yang dimaksud didalam pariwisata merupakan suatu sistem perairan, jaringan komunikasi, sumber listrik dan energi, sistem pembuangan kotoran, jasa-jasa kesehatan, jalan raya, trasportasi, keramahtamahan. Di pantai Tiram sendiri sudah mempunyai sumber air yang memadai, sumber listrik yang juga memadai, dari segi komunikasi juga tidak mengalami masalah. Berdasarkan hasil penelitian, strategi yang dilakukan dinas pariwisata dalam pengembangan Infrastruktur terhadap objek wisata di pantai Tiram ialah melakukan pembangunan infrastruktur seperti tempat ibadah yang layak toilet yang bersih, dan lahan parkir tujuannya untuk menunjang kelancaran dari pembangunan destinasi wisata tersebut, seperti yang sudah terdapat di pantai Tiram saat ini. Sedangkan penelitian yang dilakukan oleh Galuh, (2020) mengenai Strategi Dinas Pariwisata Dalam Pengembangan Infrastruktur Objek Wisata Telaga Ngebel Di Kabupaten Ponorogo bahwasannya pengembangan infrastruktur sangatlah penting untuk dilakukan karena salah satu langkah untuk menarik wisatawan untuk berkunjung ke objek wisata, selain itu fasilitas yang lengkap akan berpengaruh pada kenyamanan pengunjung. Akan tetapi masih terdapat kendala yang ditemui di wisata telaga Ngebel ini seperti salah satunya yaitu kurangnya tempat pembuang sampah dikawasan objek Wisata Telaga Ngebel, jalan yang sempit menuju objek Wisata Telaga Ngabel, dan kurangnya fasilitas tempat parkir. Jadi dapat simpulkan bahwa semangkin lengkap infrastruktur yang di miliki suatu objek wisata maka semakin meningkat tingkat 
Jurnal Ilmu Sosial dan Pendidikan

http://ejournal.mandalanursa.org/index.php/JISIP/index

Terakreditasi Peringkat 5 (No. SK: 85/M/KPT/2020)
Vol. 5. No. 1 Januari 2021

p-ISSN: 2598-9944 e- ISSN: 2656-6753 wisatawan yang berkunjung dan juga akan berpengaruh bagus pada ekonomi masyarakat.

Strategi pengembangan SDM didalam wisata Pantai Tiram ini adalah segala perspektif seseorang yang membantu berbagai aktivitas ditempat rekreasi baik bersifat nyata atau tidak nyata yang bermaksud akan mewujudkan keinginan serta dapat menciptakan kesenangan bagi pengunjung dan berpengaruh baik pada pendapatan, kelestarian lingkungan, kesejahteraan, dan budaya di tempat rekreasi tersebut.Dalam pengembangan objek wisata peran masyarakat sangat dibutuhkan khususnya sebagai pelaku usaha. Dengan adanya potensi alam yang terampil objek wisata tidak akan meningkat dengan cepat. Berdasarkan hasil penelitian Dinas Pariwisata Kabupaten Padang Pariaman melakukan pelatihan dan pembinaan kepada masyarakat yang memiliki usaha rumah makan yang ada di pantai tiram pelatihan tersebut berupa cara memberikan pelayanan kepada pembeli dan bagaimana cara menjaga kebersihan. Menurut Setiawan, (2016) dalam M.Riadhussyah, (2020) Sumber daya manusia adalah sebagai penggerak pariwisata untuk meningkatkan daya saing yaitu:1). Pengetahuan tentang tata cara pelayanan kepada wisatawan, 2). Pengetahuan tentang perlengkapan dan peralatan yang dibutuhkan saat melakukan pelayanan wisata, 3 ). pengembangan sikap atau perilaku dalam melayanai pariwisata seperti sopan santuh, ramah dan sebagainya.

Strategi pengelolaan lingkungan merupakan bagaimana cara kita menjaga kebersihan, merawat lingkungan dari sampahsampah hal ini tujuannya untuk kenyaman setiap individu. Menurut Izzato,(2016) lingkungan adalah hal yag sangat penting mengingat kontribuksi pariwisata mengenai perubahan dan pertumbuhan ekonomi di suatu daerah. Berdasarkan hasil penelitian Pengelolaan lingkungan di objek wisata pantai Tiram saat ini adalah lingkungan di objek wisata pantai tiram tidak terkelola dengan baik sesuai yang dikatakan Bapak Bahar selaku ketua Pokdarwis bahwasannya anggota pokdarwis belum ada yang mau dengan sukarela untuk mengurus dan membersihkan lingkungan pantai tiram terkhusnya pada bagian taman jalan dan gerbang masuk objek wisata, apabila lingkungan objek wisata bersih maka pengunjung akan nyaman dan bentah untuk berkunjug kembali ke objek wisata tersebut.

Strategi pengembangan Pasar dan pemasaran merupakan bagaimana cara kita untuk mengembangkan dan memperomosikan suatu produk agar produk yang kita pasarkan tersebut bisa maju dengan pesat dan mendapatkan hasil yang diinginkan. Berdasarkan hasil penelitian Pedagang rumah makan dipantai Tiram di dalam melakukan pasar dan pemasaran kepada pelanggan dengan cara memberikan pelayanan yang baik kepada pembali dengan tampilan pedagang yang rapi, permasalahannya yang terjadi sekarang masih ada juga beberapa dari pedagang yang memberikan pelayanaan yang kurang baik seperti bertutur kata yang kurang sopan, kurangnya kebersihan di dalam warungnya, penataan di dalam warungnya yang kurang rapi. Menurut Andreassen and Lindestad,(2000:11) dalam Sulfi, (2016) mengatakan bahwa suatu citra perusahaan dalam pemasaran jasa diidentifikasikan sebagai suatu faktor penting dalam mengevaluasi jasa dan perusahaannya.

Yang dimaksud dengan strategi pengembangan kelembagaan yaitu mengenai keterkaitan serta peran dari tiap-tiap komponen dalam membantu pengerjaan suatu kegiatan wisata termaksud masyarakat setempat sebagai tuan rumah, pengembangan objek wisata pantai tiram sangat didukung penuh oleh Pemerintah Daerah, Dinas Pariwisata, Wali Nagari, Masyarakat, Pemuda Wisatawan, dan Lembaga atau pun Organisasi lainnya. Bentuk dukungan yang diberikan berupa bantuan pengembangan, dan dana yang dianggarkan kepada nagari.

\section{Dampak Pengembangan Objek Wisata Pantai Tiram Terhadap Peningkatan Ekonomi Masyarakat}

Peningkatan penghasilan masyarakat adalah suatu penambahan penghasilan yang didapatkan dari usaha yang dilakukan setiap orang yang penghasilan tersebut untuk 
Jurnal Ilmu Sosial dan Pendidikan

http://ejournal.mandalanursa.org/index.php/JISIP/index

Terakreditasi Peringkat 5 (No. SK: 85/M/KPT/2020)
Vol. 5. No. 1 Januari 2021

p-ISSN: 2598-9944 e- ISSN: 2656-6753 memenuhi kebutuhannya. Semenjak pengembangan objek wisata yang dilakukan oleh Dinas Pariwisata dan Pemerintah Kabupaten Padang Pariaman dan didukung dengan infrastruktur yang sudah memadai di kawasan objek wisata Pantai Tiram ini sangat berdampak baik pada pendapatan ekonomi masyarakat jika dilihat dari sebelum Tiram diresmikannya sebagai objek wisata. Menurut Mukhsin, (2012) dalam Aprilyana, (2020) mengatakan bahwa pengembangan pariwisata sangat berpengaruh dan penting di dalam melakukan kemajuan ekonomi, upaya-upaya pelestarian sumber daya alam dan lingkungan serta juga akan berpengaruh terhadap kehidupan sosial budaya masyarakat terutama pada masyarakat lokal. Pada saat ini pengembanga objek wisata Pantai Tiram secara tidak langsung telah banyak mengubah struktur perekonomian masyarakat dengan adanya kesempatan untuk membentuk lapangan pekerjaan baru, sekarang ini masyarakat disekitar kawasan objek wisata pantai tiram yang dulunya mayoritas penduduk bekerja sebagai petani dan nelayan dan sekarang sebagian sudah beralih berdagang.

Tabel.4.1. Data Pendapatan Perekonomian Masyarakat Wisata Pantai Tiram

\begin{tabular}{|l|l|l|l|}
\hline No & Nama Rumah Makan & Penghasilan Perhari & Penghasilan Perminggu \\
\hline 1 & RM. Bahagia & Rp. 800.000 & Rp. 5.600 .000 \\
\hline 2 & RM. Lastri & Rp. 900.000 & Rp. 6.300 .000 \\
\hline 3 & RM. Neli & Rp. 650.000 & Rp. 4.550 .000 \\
\hline 4 & RM. Yeni Yana & Rp. 750.000 & Rp. 5.250 .000 \\
\hline 5 & RM. Widia & Rp. 450.000 & Rp. 3.150 .000 \\
\hline 6 & RM. Kualo Tirta & Rp. 600.000 & Rp. 4.200 .000 \\
\hline 7 & RM. Resti & Rp. 500.000 & Rp. 3.500 .000 \\
\hline 8 & RM. Sabar Menanti & Rp. 350.000 & Rp. 2.450 .000 \\
\hline 9 & RM. Aulia & Rp. 700.000 & Rp. 4.900 .000 \\
\hline 10 & RM. Dea & Rp. 300.000 & Rp. 2.100 .000 \\
\hline
\end{tabular}

(Sumber:Hasil Wawancara Peneliti Dengan Pemilik Rumah Makan)

Dari tabel diatas dapat disimpulakan bahwa pendapatan perekonomian masyarakat wisata Pantai Tiram yaitu ada sebagaian rumah makan mendapatkaan penghasilan yag terus meningkat dengan baik dan ada juga beberapa rumah makan yang mendapatkan penghasilan yang yang kecil.

Setelah infrastruktur dibangun Pemerintah Kabupaten Padang Pariaman secara bertahap sehingga infrastruktur di pantai tiram sudah lengkap seperti saat sekarang ini, masyarakat yang dulunya bekerja sebagai nelayan, petani, dan kuli bangunan. Saat sekarang mata pencarian masyarakat beralih sebagian sebagai pedagang rumah makan,pedagang minuman dan tukang parkir kendaraan bermotor. Selain itu Yang dimaksud dengan penambahan jenis pekerjaan adalah seseorang atau pemerintah yang membuka lapangan pekerjaan untuk orang-orang yang dulunya tidak memiliki pekerjaan sehingga orang-orang tersebut memiliki penghasilan dari apa yang mereka usahakan. Menurut Asnurul, (2019) mengatakan bahwa didalam meningkatkan pendapatan masyarakat tentu akan dibukanya lapangan pekerjaan yang bertujuan untuk merubah keadaan perekonomian di suatu objek wisata.

Menurut Nurrohmah, (2015) dalam Fitriani, (2016) menyatakan bahwa peningkatan usaha adalah suatu bentuk usaha yang dilakukan untuk dapat berkembangan menjadi lebih baik lagi danlam mencapai pada satu titik atau punjak menuju kesuksesan. Dimana perkembangan suatu usaha tersebut juga dapat dilihat dari jumlah pendapatan, nilai penjualan, laba, barang yang terjual dan perluasan usaha selama jangka waktu tertentu.Peningkatan jumlah pedagang sangat meningkat pesat di Pantai Tiram semenjak tingkat kunjungan mulai dikenal masyarakat luas dan didukung juga dengan infrastruktur yang bagus dan lengkap yang dulunya di Pantai Tiram hanya ada 3 rumah makan seiring dengan pengembangan yang di lakukan Pemerintah Kabupaten Padang Pariaman peningkatan rumah makan dan pedagang di pantai tiram pun mulai meningkat.

\section{KESIMPULAN}

Strategi yang dilakukan Dinas Pariwisata Kabupaten Padang Pariaman didalam melakukan pengembangan objek wisata pantai tiram. Yaitu strategi pengembangan fasilitas di pantai tiram sudah mulai memadai seperti adanya board walk, plaza kuliner di objek 
Jurnal Ilmu Sosial dan Pendidikan

http://ejournal.mandalanursa.org/index.php/JISIP/index

Terakreditasi Peringkat 5 (No. SK: 85/M/KPT/2020)
Vol. 5. No. 1 Januari 2021

p-ISSN: 2598-9944 e- ISSN: 2656-6753 wisata Pantai Tiram, strategi pengembangan infrstruktur di Pantai Tiram juga sudah lengkap seperti toilet, musholla. strategi pengembangan SDM Dinas Pariwisata Kabupaten Padang Pariaman memberikan pelatihan kepada setiap pedagang di objek wisata Pantai Tiram, strategi pengembangan pengelolaan lingkungan di objek wisata Pantai Tiram masih kurang terkelola seperti terlihatnya taman-taman yang kurang terjaga kebersihannya, strategi pengembangan pasar dan pemasaran di wisata Pantai Tiram ini Dinas Pariwisata Kabupaten Padang Pariaman melakukan promosi wisata seperti melalui iklan, radio, baliho, melalui dan media sosial seperti instagram, facebook, browsure dan menghadiri setiap event yang ada di luar kota,belum lama ini tim Dinas Pariwisata mendapat undangan untuk menghadiri kelender event wisata di ancol di dalam pameran event tersebut Dinas Pariwisata juga memliki peluang untuk mempromosikan wisata kuliner Pantai Tiram di luar kota tersebut dengan cara Tim Dinas Pariwisata memberikan browsure kepada wisatawan yang berada di ancol tersebut. Selanjutnya Kelompok Sadar Wisata (Pokdarwis) juga melakukan hal yang sama dengan dinas pariwisata pokdarwis dengan anggota juga melakukan promosi baik melalui media sosial, koran dan lain sebagainya. strategi pengembangan kelembagaan yang ikut serta di objek wisata pantai tiram ini yaitu dinas PU, Dinas Lingkungaan Hidup. Dampak dari pengembangan yang dilakukan dari Pemerintah Kabupaten Padang Pariaman, Dinas Pariwisata dan Pokdarwis itu sudah cukup berdampak baik bagi masyarakat setempat khususnya bagi para pedagang rumah makan dari yang awalnya ada 3 rumah makan dan sekarang sudah mencapai 17 rumah makan yang berada di Pantai Tiram dan dari pengahasilan per rumah makan dulunya hanya Rp. 150.000 per hari dan sekarang sudah mencapai Rp.850.000 perharinya dapat dilihat bahwa dampak dari pengembangan objek wisata Pantai Tiram ini sudah berdampak baik bagi masyarakat di kawasan objek wisata Pantai Tiram. Tingkat pengunjung wisata pantai tiram saat ini masih naik turun kadang-kadang tingkat kunjungan wisata rame terkadang juga sepi sama halnya degan pendapatan masyarakat wisata pantai tiram ekonominya pun juga masih naik turun.

\section{SARAN}

Diharapkan Pokdarwis (kelompok sadar wisata) yang telah dibentuk ini bisa berpartisipasi di dalam pengelolaan lingkungan agar terjaga kebersihan objek wisata pantai tiram karena fasilitas di objek wisata pantai tiram ini sudah memadai sangat disayangkan jika tidak terawat dengan baik.

Objek wisata yang diharapkan dapat diperbaiki secepat mungkin, dari segi gerbang masuk wisata yang mulai tidak membaik dan bord walk yang mulai rusak akibat kurang terjaga. Masyarakat yang berada di objek wisata pantai tiram agar lebih sadar akan kebersihan serta menjaga fasilitas yang sudah memadai saat ini di pantai tiram.

\section{DAFTAR PUSTAKA}

Aprilyana Selin Marsela. 2020. Dampak Pengembangan Objek Wisata Goa Kreo Bagi Kesejahteraan Masyarakat Di Kelurahan Kandri Kecamatan Gunung Pati Kota Semarang. Journal Unnes ac.id. Vol 9. No 2.

Ari Welianto. 2020. http://www.kompas.com. Jenis-Jenis Kegiatan Ekonomi Masyarakat. akses 19 Maret 2020 19:45 WIB.

Asnurul Novia Narendra. 2019. Kepemilikan Serta Pembentukan Modal Sosial Oleh Wisatawan Dalam Memilih House Of Sampoerna Sebagai Daya Tarik Wisata. Jurnal Pariwisata Pesona. Vol 4. No 1.

Atun Yulianto. 2020. Strategi Pemeliharaan Dan Pengembangan Fasilitas Wisata Bagi Kenyamanan Pengunjung Pule Payung Yogyakarta. Pariwisata. Vol. 7. No 2.

Dewi Yanti Ratih Indonesiani. 2015. Analisis Pengembangan Objek Wisata Tanjung 
Jurnal Ilmu Sosial dan Pendidikan

http://ejournal.mandalanursa.org/index.php/JISIP/index

Terakreditasi Peringkat 5 (No. SK: 85/M/KPT/2020)
Vol. 5. No. 1 Januari 2021

p-ISSN: 2598-9944 e- ISSN: 2656-6753
Karang Dikecamatan Banawa

Donggala. E-Jurnal Katologis. Vol 3.

No 7 ..

Dispapora. Padang pariaman kabupaten.go.id.

Fitriani Prastiawati. 2016. Peran Pembiayaan

Baitul Maal Wat Tamwil Terhadap

Perkembangan Usaha Dan

Peningkatan Kesejahteraan

Anggotanya Dari Sektor Mikro

Pedagang Pasar Tradisional. Jurnal

Akuntansi Dan Investasi. Vol 17. No

2.

Galuh Istu Sripambudi. 2020. Strategi Dinas

Pariwisata Dalam Pengembangan

Infrastruktur Objek Wisata Telaga

Ngebel Di Kabupaten Ponorogo.

Jurnal Ilmu Sosial Dan Humaniora.

Vol 3. No 1.

Isma Adila. 2011. Spasialis Dalam Ekonomi

Politik Komunikasi (Studi Kasua

MRA Media). Jurnal Ilmu

Komunikasi. Vol 1. No 1.

Izzato Millati. 2016. Akuntansi Lingkungan Sebagai Strategi Pengelolaan

Lingkungan Daerah Wisata Gunung Ijen Kabupaten Banyuwangi. Jurnal Riset Akuntansi Dan Bisnis Airlangga. Vol 1. No 1.

Juita L.D. Bussie. 2018. Strategi

Pengembangan Objek Wisata Dalam Upaya Peningkatan Kunjungan (Studi Pada Objek Wisata Pantai Oetune Kabupaten TTS) Journal Of Management (SME's).Vol 6. No 1.

Khusnul Khotimah. 2017. Strategi Pengembangan Destinasi Pariwisata Budaya (Studi Kasus Pada Kawasan Situs Trowulan Sebagai Pariwisata Budaya Unggul Di Kabupaten Mojokerto) Jurnal Administrasi Bisnis (JAB) Vol 41. No 1

M. Riadhussyah. 2020. Pengetahuan Sumber Daya Manusia Di Bidang Wisata Halal Dalam Menghadapi Revolusi Industri 4.0. Jurnal MSDA Manajemen Sumber Daya Aparatur. Vol 8. No 1.
Moleong. 2010. Metode Penelitian Kualitatif. Bandung: Remaja Risda Karya.

Muhammad Arif, dkk. 2017. Strategi Pengembangan Objek Wisata Sumedang Dikecamatan Ranag Pesisir Selatan. Jurnal Kepemimpinan Dan Pengurus Sekolah . Vol 2. No 2.

Rony ika setiawan. 2016. Pengembangan Sumber Daya Manusia Di Bidang Pariwisata: Perspektif Potensi Wisata Daerah. Jurnal Penelitian Manajemen Sterapan (PENATARAN). Vol 1. No 1 .

Sefira Ryalita Primadany. 2013. Analisis Strategi Pengembangan Pariwisata Daerah (Studi Pada Dinas Kebudayaan Dan Pariwisata Daerah Kabupaten Nganjuk). Jurnal Administrasi Publik (JAP). Vol 1. No 4.

Sugiono .2012. Metode Penelitian Pendidikan. Bandung: Alfabeta

Sulfi Abdulhaji. 2016. Pengaruh Atraksi, Aksesibilitas, Dan Fasilitas Terhadap Citra Objek Wisata Danau Tolire Besar Di Kota Ternate. Jurnal Penelitian Humano. Vol 7. No 2.

Undang-Undang Nomor 10 Tahun 2009 Tentang Kepariwisataan. 